\title{
ESTUDO PRELIMINAR DO PROCESSO DE INTRODUÇÃO DE NOVAS ATIVIDADES PRODUTIVAS: O CASO DA PIMENTA-DO- REINO NO ASSENTAMENTO LUIZ INÁCIO EM PARAGOMINAS -
}

\section{PA}

Cleber Assis dos Santos ${ }^{1}$, Livia de Freitas Navegantes Alves ${ }^{2}$, Monique Helen Cravo Soares Farias $^{3}$, José Bruno Santos Pinheiro ${ }^{4}$

(1 - Universidade Federal do Pará, Especialista em Agriculturas Amazônicas e Desenvolvimento Agroambiental, cleber_ufpa@yahoo.com.br; 2 - Universidade Federal do Pará, Professor Adjunto do Núcleo de Ciências Agrárias e Desenvolvimento Rural lnavegantes@ufpa.br; 3 - Universidade do Estado do Pará, Mestranda do Programa de Ciências Ambientais, adm.moniquefarias@gmail.com; 4 - Universidade Federal Rural da Amazônia, Especialista em Agriculturas Amazônicas e Desenvolvimento Agroambiental, jbrunopinheiro@hotmail.com)

Resumo: Em Paragominas, município do Nordeste do Pará, o processo de introdução de novas atividades produtivas é comum em lotes de agricultores familiares. Nesse sentido, se destaca o cultivo da pimenta-do-reino. Este estudo tem como objetivo entender como se processa a introdução de uma nova atividade produtiva e os motivos dos agricultores em introduzirem determinadas mudanças nos sistemas de produção. A pesquisa de campo foi realizada com agricultores do assentamento Luiz Inácio, onde foram aplicados 71 questionários para caracterização geral dos sistemas de produção. Através da aplicação dos questionários foram identificados agricultores que tinham introduzido novas atividades, destacando-se a pimenta-do-reino. A sistematização dos dados revelou que $44 \%$ do total de agricultores entrevistados iniciaram uma nova atividade produtiva, dentre eles $29 \%$ cultivam a pimenta-do-reino. Os resultados mostram que o cultivo da pimenta-do-reino está crescendo no assentamento, principalmente pela estabilidade e alto preço de comercialização, contribuindo para o desenvolvimento econômico dos agricultores e possibilitando-lhes segurança financeira. É extremamente importante entender as possibilidades de mudança nos sistemas

Artigo recebido para publicação em 08 de Maio de 2015

Artigo aprovado para publicação em 10 de Outubro de 2015 


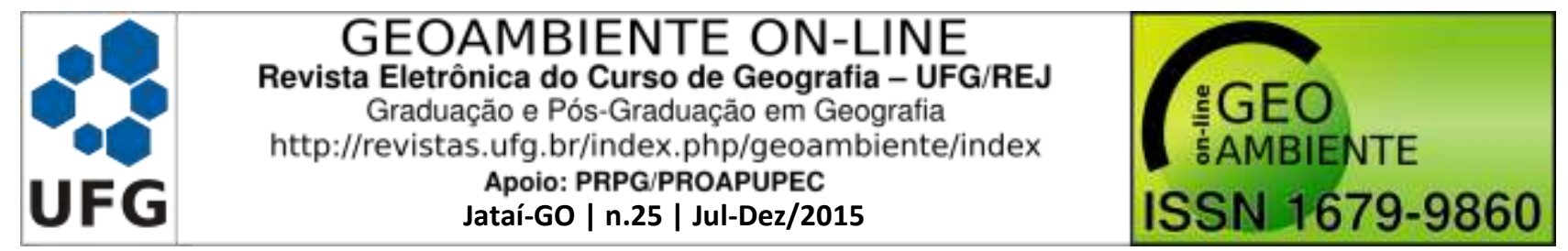

de produção para poder subsidiar um apoio mais realista aos agricultores no planejamento e implementação de novas atividades.

Palavras-chave: Nova atividade produtiva, pimenta-do-reino, preço estável.

\title{
PRELIMINARY STUDY OF THE PROCESS OF INTRODUCTION OF NEW PRODUCTIVE ACTIVITIES: THE CASE OF BLACK PEPPER IN THE SETTLEMENT LUIZ INÁCIO IN PARAGOMINAS - BRAZIL
}

\begin{abstract}
In Paragominas, city in the Northeast of the State of Pará, the process of introduction of new productive activities is common in family farmers land. In this sense, it is worth highlighting the cultivation of black pepper. This study aims to understand how it works the introduction of a new productive activity and the reasons why farmers introducing certain changes in their production systems. He field research was conducted with farmers from the settlementg Luiz Inacio, where 71 questionnaires were applied to general characterization of the production systems. Through the application of thequestionnaires, it was possible to identify farmers that had introduced new activities, especially the cultivation of black pepper. The data systematization revealed that $44 \%$ of interviewed farmers began a new productive activity, including $29 \%$ that cultivate the black pepper. The results show that the cultivation of black pepper is growing in this settlement, particular by the stability and high trading price, contributing to the economic development of farmers and enabling them financial security. It is extremely important to understand the possibilities for change in the production systems in order to subsidize a realistic support to farmers in the planning and implementation of new activities.
\end{abstract}

Key words: New productive activity, Black pepper, Stable price.

\section{UN ESTUDIO DEL PROCESO DE INTRODUCCIÓN DE NUEVAS ACTIVIDADES PRODUCTIVAS: EL CASO DE PIMIENTA NEGRA EN EL ASENTAMIENTO LUIZ INÁCIO EN PARAGOMINAS - BRASIL}

Resumen: En Paragominas, ciudad localizada en la región nordeste de Pará, el proceso de introducción de nuevas actividades productivas es común en una gran cantidad de parcelas de tierra de agricultores familiares. En este sentido, destaca el cultivo de pimienta negra. Este 


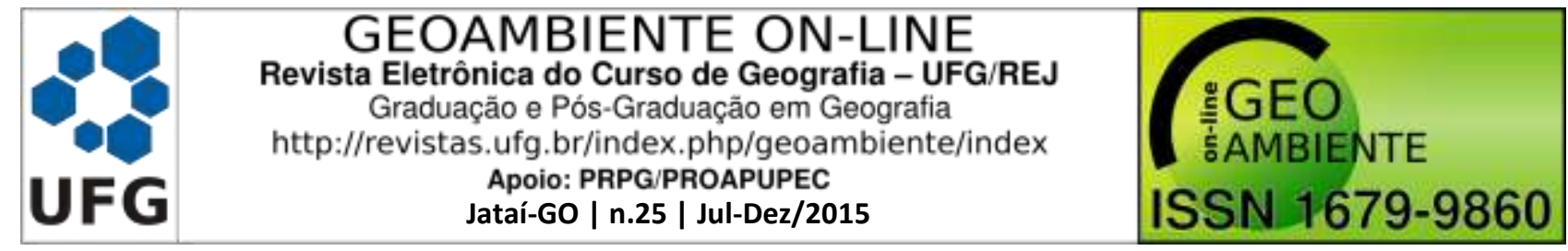

estudio tiene como objetivo comprender cómo se procesa la introducción de una nueva actividad productiva y las razones de los agricultores en la introducción de ciertos cambios en los sistemas de producción. La investigación de campo se llevó a cabo con los agricultores del asentamiento Luiz Inácio, donde se aplicaron 71 cuestionarios a la caracterización general de los sistemas de producción. A través de los cuestionarios fueron identificados agricultores que habían introducido nuevas actividades, especialmente la pimienta negra. La sistematización de los datos reveló que $44 \%$ de los agricultores entrevistados comenzó una nueva actividad productiva, incluyendo $29 \%$ que cultivan la pimienta negra. Los resultados muestran que el cultivo de la pimienta negra está creciendo en el asentamiento, en particular por la estabilidad y alto precio de cotización, lo que contribuye al desarrollo económico de los agricultores y permitiéndoles la seguridad financiera. Es muy importante entender las posibilidades de cambio en los sistemas de producción con el fin de subsidiar un soporte más realista a los agricultores en la planificación e implementación de nuevas actividades.

Palabras Clave: Nueva actividad productiva, Pimienta negra, Precio estable.

\section{Introdução}

O município de Paragominas é um dos mais importantes do estado do Pará, principalmente por ser pioneiro em muitas iniciativas relativas à produção agrícola, como pesquisas agropecuárias na Amazônia, financiamento para o plantio de seringueira na agricultura familiar, introdução de pastagens plantadas em terra firme, implantação do Programa Estadual Municípios Verdes (BARBOSA \& FALESI, 2011), e pela repercussão de sua recente estratégia política de proteção das florestas.

De acordo com Almeida \& Uhl (1996) apud Pinto et al. (2009), em 1995, já havia em Paragominas mais de 20 colônias agrícolas, com área média de 2.500 hectares cada, ocupando no mínimo 50 mil hectares do município. Desde então, algumas dessas colônias se tornaram projetos de assentamento, formaram-se novas colônias e outras se expandiram à medida que a população se reproduziu e/ou novas famílias se instalaram na área.

Estima-se que 8,2\% (159.600 hectares) de Paragominas estejam ocupados por pequenos produtores rurais; 5,7\% (110.600 hectares) estejam dentro dos projetos de assentamento; e 2,5\% (49.000 hectares) estejam nas colônias agrícolas fora das áreas de assentamento (PINTO et al., 2009). 


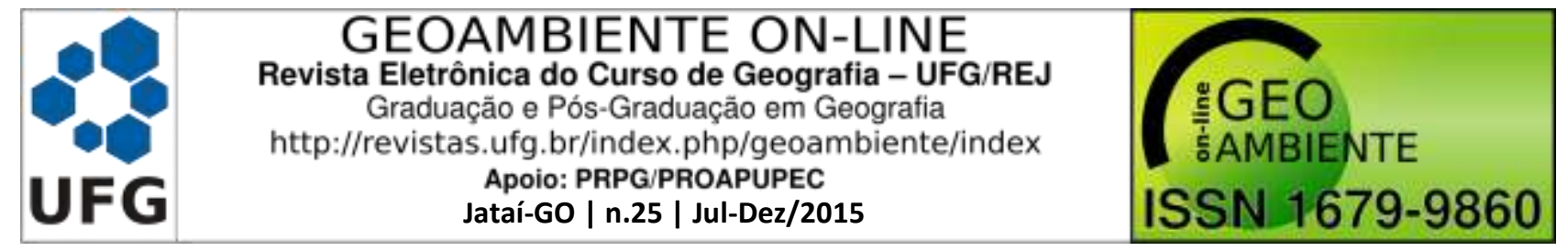

As culturas de arroz (Oryza sativa L), feijão (Phaseolus vulgaris L.), mandioca (Manihot esculenta Crantz) e milho (Zea mays L.) continuam sendo as mais praticadas entre os pequenos produtores agrícolas. Essas culturas visam primeiramente garantir a segurança alimentar da família e, quando há excedente de produção, gerar renda para suprir outras necessidades da unidade familiar e produtiva. Dentre esses cultivos agrícolas, a mandioca é a mais amplamente comercializada sob a forma de farinha (PINTO et al., 2009).

Dentro do assentamento Luiz Inácio no município de Paragominas, notou-se que nos últimos dois anos o processo de introdução de novas atividades produtivas está crescendo. Segundo Reinjntjes et al. (1994), através de processos de adaptação e inovação os agricultores buscam sistemas agrícolas diversos, onde cada um se adapta ao seu ambiente econômico, ecológico, social, cultural e político.

De acordo com o Manual de Oslo (2005), entende-se por inovação a implementação de um produto (bem ou serviço) novo ou significativamente melhorado onde a inovação é um processo contínuo e, por isso, difícil de ser mensurado.

Iniciar uma nova atividade produtiva não é simples, pois os riscos que as novas atividades trazem, devem ser muito bem delimitados, já que suas consequências podem ser muito expressivas para os agricultores (LEFORT, 1990).

A nova atividade produtiva identificada dentro do assentamento é o cultivo da pimenta-do-reino. O Pará é destaque no cenário nacional no que se refere a essa cultura, sendo o maior produtor do Brasil, respondendo por $76 \%$ da safra nacional. A maior parte da produção, cerca de $90 \%$, é desenvolvida por pequenos agricultores (REVISTA CAMPO E NEGÓCIO, 2012).

A cultura da pimenta-do-reino foi introduzida no estado do Pará na década de 1930 pelos imigrantes japoneses. A partir dessa data o município de Tomé-Açú tornou-se o maior polo de produção, permitindo ao Brasil, na década de 80 , alcançar a posição de maior produtor mundial (EMBRAPA/SEDE, 2004). Na Transamazônica houve, na década de 1980 um grande ciclo da pimenta, porém na década de 90, o preço dessa cultura sofreu grande queda, devido a inflação da época (NASCIMENTO et al., 2007).

No Pará, existem áreas plantadas com pimenta-do-reino em quase todas as regiões do Estado, sendo que os principais municípios produtores estão situados no nordeste do Estado, especialmente nos municípios de Tomé-Açú, Igarapé-Açú, Santa Maria do Pará, Bragança, 


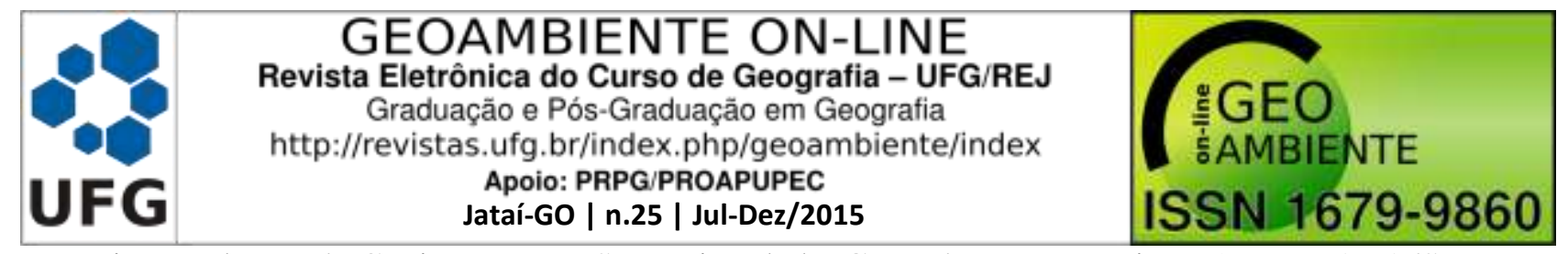

Ipixuna do Pará, Capitão Poço, São Miguel do Guamá e Paragominas (EMBRAPA/SEDE, 2004).

É necessário entender as possibilidades de mudança nos sistemas de produção para poder subsidiar agricultores em introduzirem determinadas mudanças nos sistemas de produção. Neste sentido, é primordial levantar informações junto aos agricultores sobre o início do cultivo da pimenta na região e detectar quais as situações que levaram estes agricultores iniciar o cultivo da pimenta-do-reino.

\section{Materiais e métodos}

O presente trabalho foi realizado no assentamento Luiz Inácio, no município de Paragominas (Figura 1). O acesso ao assentamento no período chuvoso, que vai de dezembro até maio, e bastante difícil, uma vez que as estradas não são pavimentadas.

Figura 1 - Mapa da localização do assentamento Luiz Inácio em Paragominas - PA

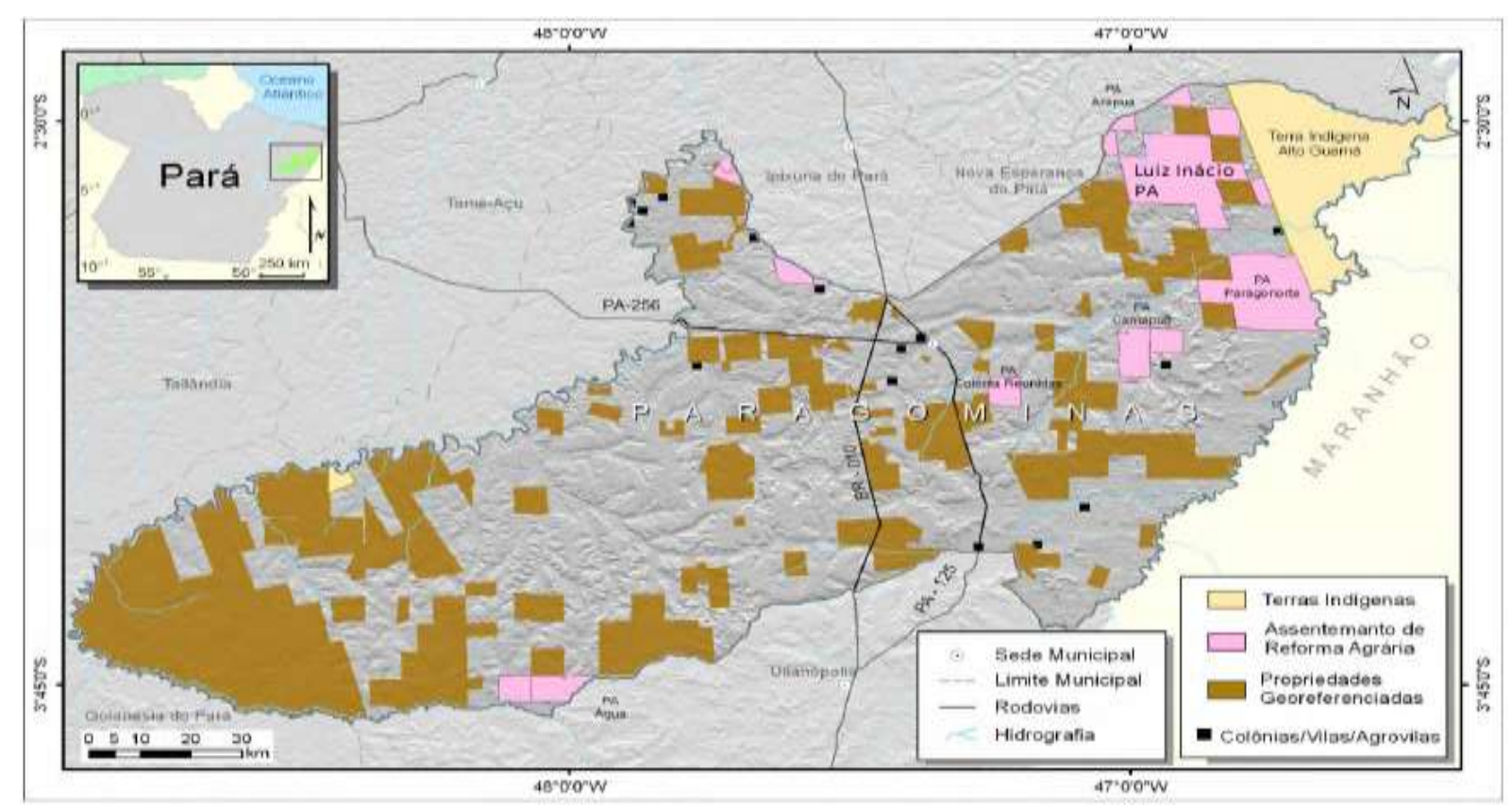

Fonte: IMAZON (2009)

$\mathrm{Na}$ primeira fase da pesquisa foram aplicados 71 questionários por oito discentes do curso de Especialização em Agriculturas Amazônicas e Desenvolvimento Agroambiental da UFPA, distribuídos em todo o assentamento, no período de 26 a 30 de novembro de 2012, compreendendo propriedades situadas em áreas sobre influência das vilas Ribeirinho, 


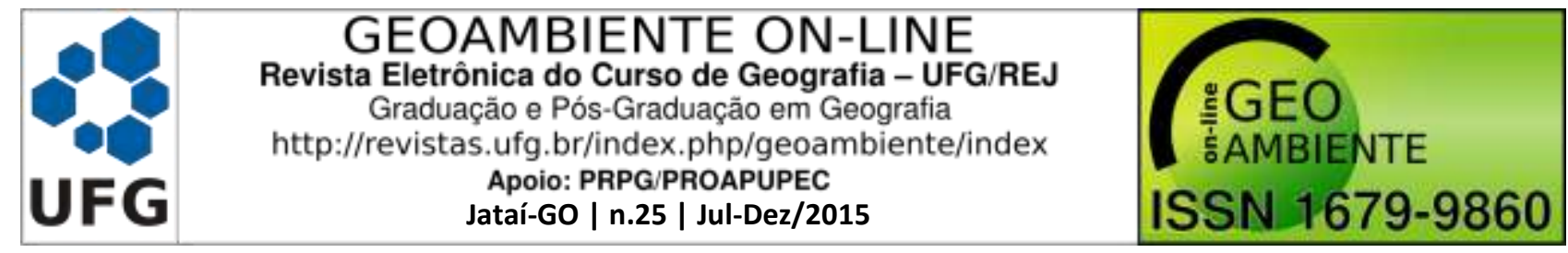

Paragonorte, Nova Jerusalém e Cacimbão. Cada questionário continha 73 questões, com perguntas sobre a estrutura familiar, a renda, a infraestrutura, o uso da terra, os sistemas de produção atuais e suas mudanças ao longo dos anos e sobre as perspectivas e dificuldades encontradas pelas famílias no assentamento. Foram aplicados em média 18 questionários por vila.

Os dados foram tratados tanto no nível do assentamento quanto das diferentes Vilas, tendo, como enfoque principal, as novas atividades produtivas no assentamento. Posteriormente, procedeu-se a uma segunda fase de levantamento de dados em campo, no período de 22 a 25 de janeiro de 2013, quando foram realizadas entrevistas com agricultores que introduziram a inovação produtiva identificada na fase anterior como mais expressiva.

As entrevistas foram baseadas em um roteiro com trinta perguntas feitas a produtores que tem como inovação o cultivo da pimenta-do-reino. As entrevistas eram compostas de perguntas como: quando se iniciou a mudança na atividade produtiva; que tipo de família iniciou esse processo; quais os motivos que levaram a essa mudança; sobre as perspectivas futuras desse investimento, enfim, procurar entender as razões dos entrevistados para introdução da pimenta. Essas entrevistas tiveram como objetivo identificar como as mudanças de atividade produtiva se processaram no assentamento Luiz Inácio.

Com posse nos dados da pesquisa de campo, foi realizado tratamento estatístico descritivo. Além da realização de pesquisa de campo, foi realizada uma revisão na literatura com o objetivo de aporte teórico sobre o tema.

\section{Resultados e discussão}

\section{Caracterização geral dos agricultores do assentamento}

A maioria das famílias é originária de municípios próximos ao assentamento (Figura 2), como Nova Esperança do Piriá, Garrafão do Norte, cidades do Maranhão, Capitão Poço, Paragominas, Ourém e demais cidades do Brasil.

As principais fontes de renda (Figura 3) são provenientes de atividades agropecuárias oriundas dos estabelecimentos próprios, auxílios do governo, venda de mão-de-obra, salário formal, aposentadoria e pensão. Em média, a renda das famílias do Assentamento está em torno de $\mathrm{R} \$ 880,00$ mensais. 


\begin{tabular}{|c|c|c|}
\hline IF & $\begin{array}{c}\text { GEOAMBIENTE ON-LINE } \\
\text { Revista Eletrônica do Curso de Geografia - UFG/REJ } \\
\text { Graduaçáa e Pós-Graduaçăo em Geografia } \\
\text { http://revistas.ufg.br/index.php/geoambiente/index } \\
\text { Apoio: PRPG/PROAPUPEC } \\
\text { Jatai-GO | n.25 | Jul-Dez/2015 }\end{array}$ & $\begin{array}{l}\text { LGEO } \\
\text { ISAMBIENTE } \\
\text { ISSN } 1679-9860\end{array}$ \\
\hline
\end{tabular}

Figura 2 - Origem das famílias do assentamento

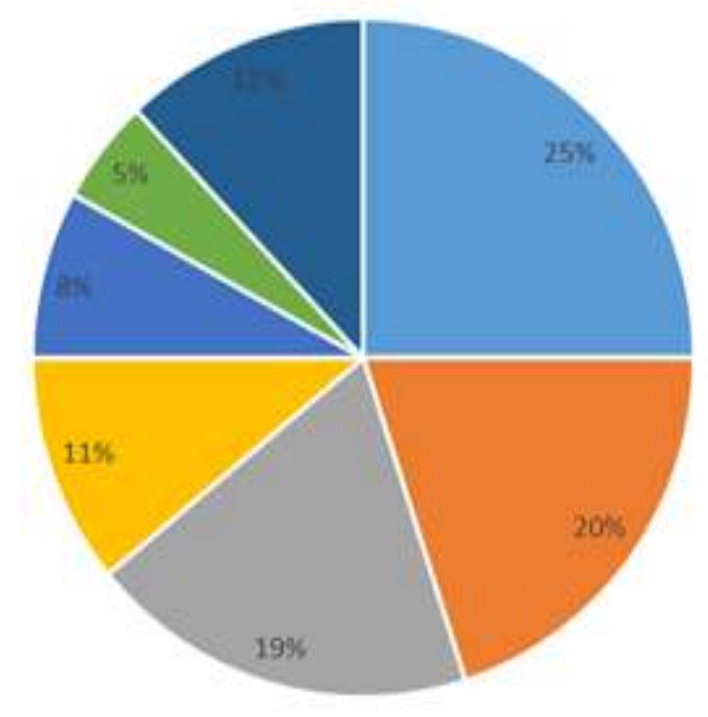

- Nova Esperança do Piriá

- Garrafầo do Norte

- Cidades do Maranhã

* Capitão Poço

- Paragominas

" Ourém

- Demais cidades do Brasil

Fonte: Pesquisa de Campo da Especialização em Agriculturas Amazônicas e Desenvolvimento Agroambiental da Universidade Federal do Pará (2012)

Figura 3 - Principais fontes de renda das famílias do assentamento

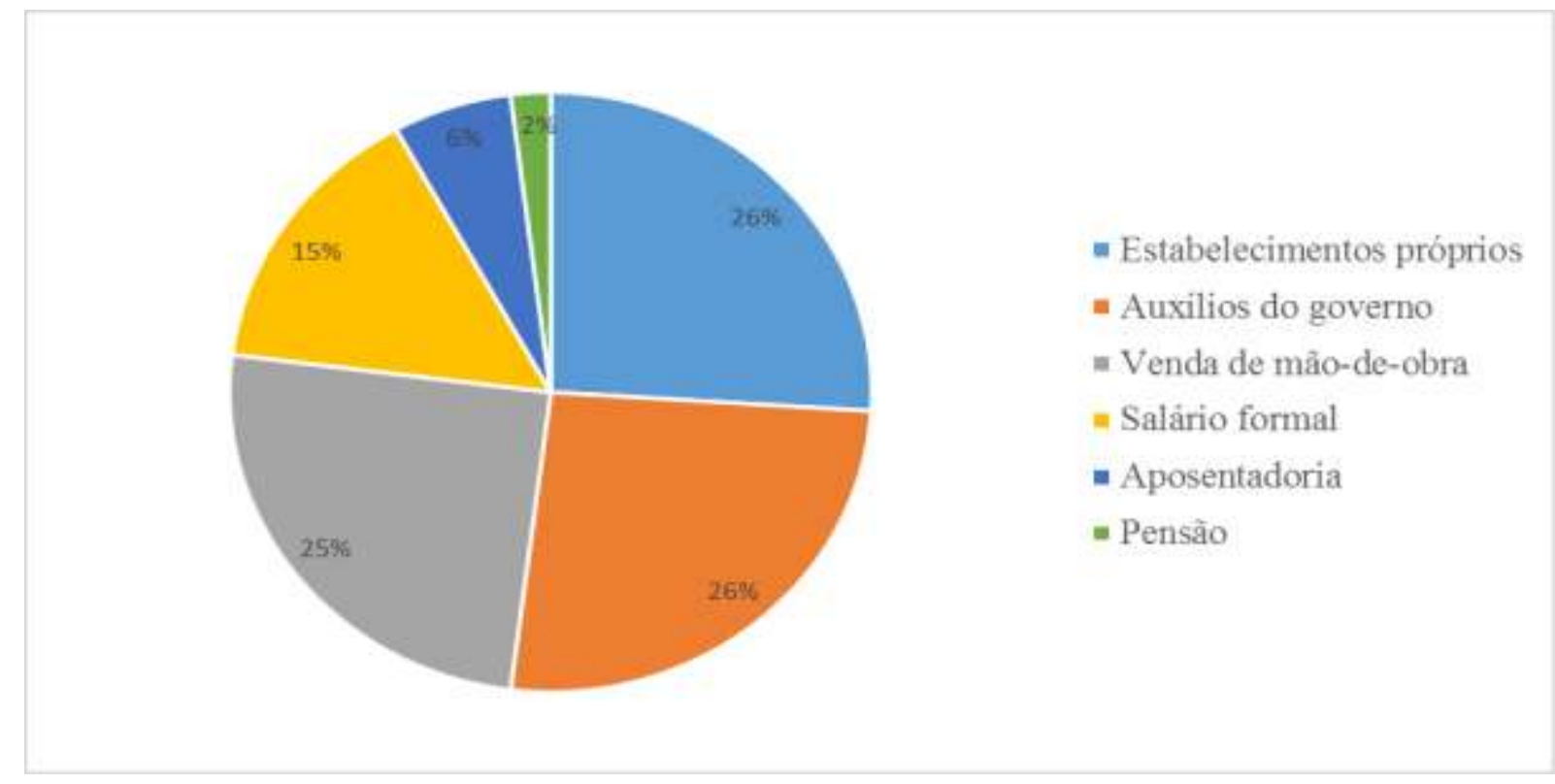

Fonte: Pesquisa de Campo da Especialização em Agriculturas Amazônicas e Desenvolvimento Agroambiental da Universidade Federal do Pará (2012)

As principais atividades produtivas implantadas logo na chegada dos agricultores no lote (Figura 4) foram a roça de mandioca, o milho, o arroz, o feijão, a pimenta-do-reino e outras culturas. 


\begin{tabular}{|c|c|c|}
\hline IF & $\begin{array}{c}\text { GEOAMBIENTE ON-LINE } \\
\text { Revista Eletrônica do Curso de Geografia - UFG/REJ } \\
\text { Graduaçáa e Pós-Graduaçăo em Geografia } \\
\text { http://revistas.ufg.br/index.php/geoambiente/index } \\
\text { Apoio: PRPG/PROAPUPEC } \\
\text { Jatai-GO | n.25 | Jul-Dez/2015 }\end{array}$ & $\begin{array}{l}\text { LGEO } \\
\text { ISAMBIENTE } \\
\text { ISSN } 1679-9860\end{array}$ \\
\hline
\end{tabular}

Figura 4 - Principais atividades produtivas implantadas na chegada ao lote

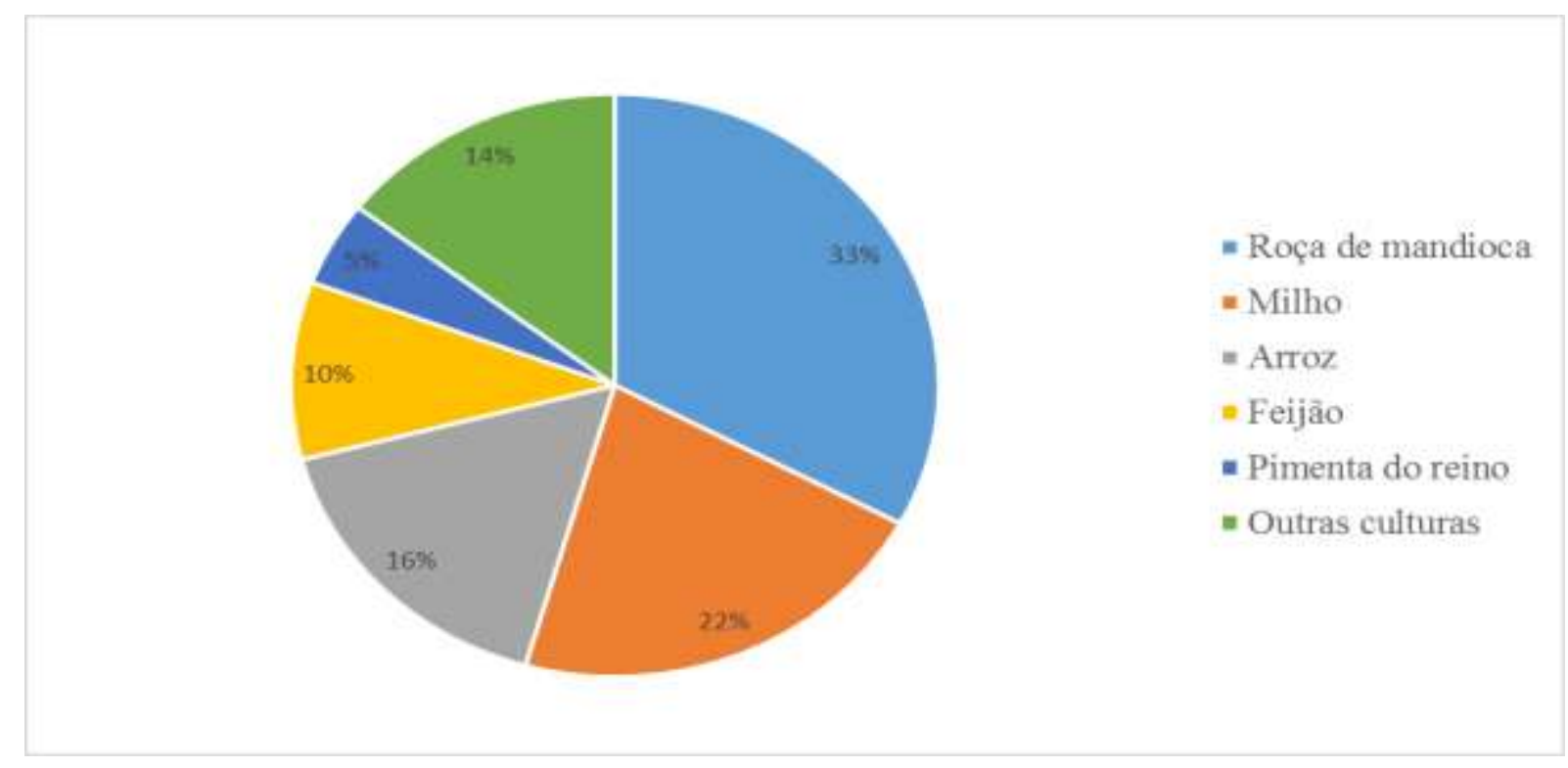

Fonte: Pesquisa de Campo da Especialização em Agriculturas Amazônicas e Desenvolvimento Agroambiental da Universidade Federal do Pará (2012)

Após o período de instalação na propriedade, 31 famílias (44\% do total das famílias entrevistadas) iniciaram uma nova atividade produtiva em seu lote (Figura 5), sendo essas atividades o cultivo da pimenta-do-reino, pecuária, roçado de mandioca, feijão, milho, banana, arroz e outras novas atividades.

Figura 5 - Novas atividades produtivas implantadas no lote

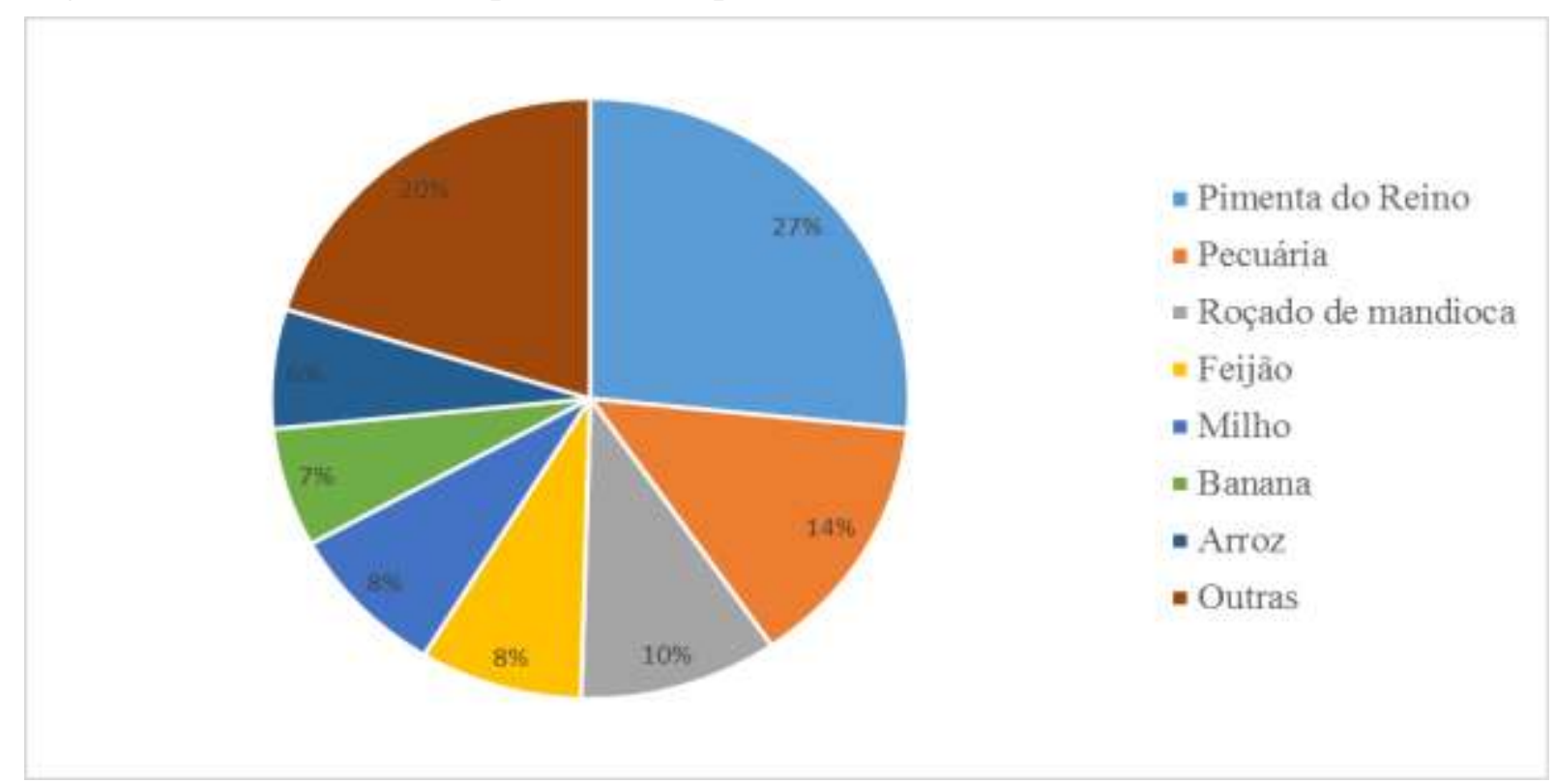

Fonte: Pesquisa de Campo da Especialização em Agriculturas Amazônicas e Desenvolvimento Agroambiental da Universidade Federal do Pará (2012) 


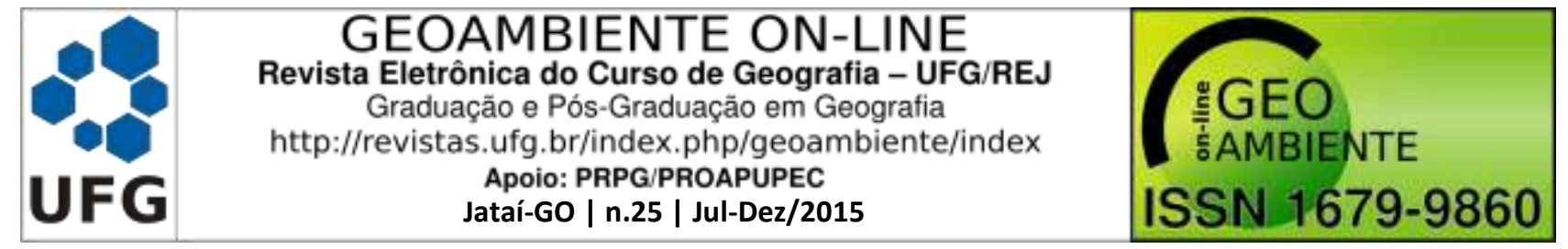

Segundo os próprios moradores do assentamento, a escolha da nova atividade produtiva, se dava pela principalmente pelo retorno financeiro e facilidade no manejo que as características físicas da região proporcionavam (clima e solo).

Caracterização de uma nova atividade produtiva no assentamento: o cultivo da pimenta-doreino

Destacou-se como inovação produtiva na região, o cultivo da pimenta-do-reino, praticado por $29 \%$ das 31 famílias que introduziram uma nova atividade produtiva. A partir de novas entrevistas realizadas tendo como amostra oito agricultores familiares que cultivam a pimenta-do-reino, foi possível obter dados mais refinados, tendo em vista o conhecimento sobre as peculiaridades desse cultivo no sistema produtivo dos produtores.

Foram entrevistadas ao todo oito famílias que cultivam a pimenta-do-reino, distribuídas nas Vilas Ribeirinho e Cacimbão, essas famílias chegaram no assentamento no período compreendido entre os anos de 1998 e 2009.

Atualmente, essas famílias veem na pimenta-do-reino o suporte financeiro e a reserva de valor para a manutenção da renda e como alternativa para investir em produtos para o lar e na criação de gado bovino. Existe uma estratégia dos produtores de investimento na pecuária, entretanto, os investimentos nessa atividade não levarão a exclusão da pimenta dentro do sistema.

A região apresenta uma boa produtividade. As plantações mais antigas da região dão bons resultados, um exemplo disso é um dos produtores que no ano de 2012 retirou $5 \mathrm{~kg}$ de pimenta verde de cada pé (para cada $3 \mathrm{~kg}$ de pimenta verde se retira $1 \mathrm{~kg}$ de pimenta seca, razão de 3:1). Em média, dependendo do cultivar, segundo Poltronieri (2005) cada planta apresenta produção média de 3,5 kg na Amazônia Oriental.

Dados da pesquisa mostram o recente início da cultura da pimenta-do-reino como nova atividade produtiva na região. Dos agricultores entrevistados na pesquisa, $67 \%$ iniciaram o cultivo da pimenta entre 2011 e 2012.

Um dos grandes motivos que impulsionaram os agricultores a iniciar o cultivo da pimenta-do-reino é sem dúvida a estabilidade que o preço vem mantendo. A maioria dos agricultores entrevistados $(75 \%)$ se referiram à estabilidade e o alto preço como motivo para 
iniciarem a produção de pimenta. Atrelado ao preço eles destacaram também a boa produção alcançada pelos pioneiros da atividade no local. Segundo os próprios produtores locais, a média que a pimenta seca está sendo vendida atualmente (2012) é de R $\$ 11,00 / \mathrm{kg}$, sem custo de transporte.

Durante os anos de 2002 e 2011 a pimenta-do-reino obteve uma grande variação de preços no estado do Pará, oscilando de um mínimo de R\$4,97/kg, em outubro de 2005, e um máximo de R\$ 16,27/kg em novembro de 2002 (SILVA et al., 2012). Dados sobre as séries temporais referentes a evolução do preço da pimenta-do-reino no Brasil compreendido entre os períodos de jan./1980 a maio/2009 (Figura 6), apresentados no trabalho de Figueiras et al. (2009), mostram que os preços são bastante similares com os do estado do Pará, apresentados por Silva et al. (2012) no mesmo período.

Figura 6 - Valor da pimenta-do-reino no Brasil entre jan./1980 a maio/2009

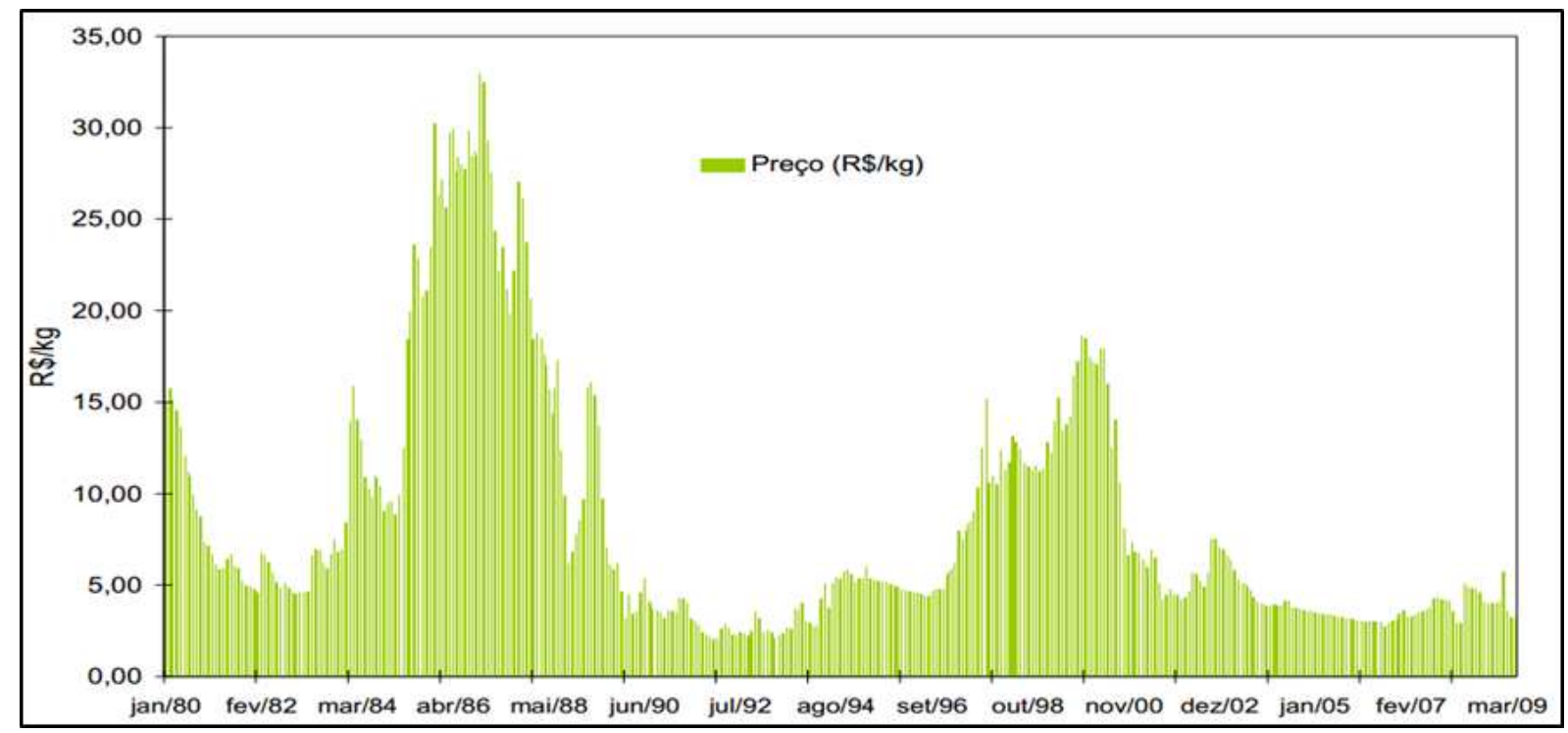

Fonte: Elaborado por Filgueira et al., (2009), a partir de dados do IPEA de 2009

Mesmo correndo o risco de o preço cair bruscamente, segundo os agricultores, o cultivo da pimenta não deverá ser abandonado, eles podem até não aumentar a plantação, entretanto irão manter o pimental na mesma proporção. Quando o lucro dos produtores era reduzido em consequência dos preços baixos, comparado com outras "commodities" a produção da pimenta-do-reino ainda é um negócio vantajoso (HOMMA et al., 2005). 


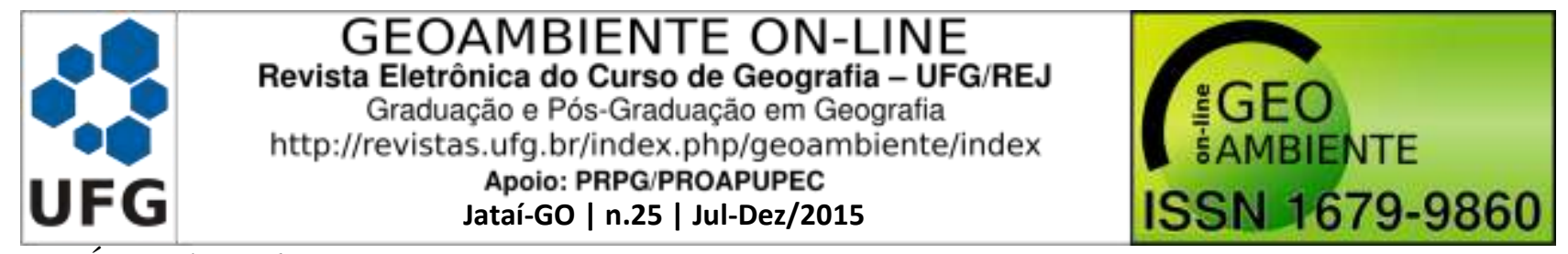

Área plantada

Segundo dados da pesquisa realizada em campo, a área de pimenta-do-reino no assentamento vem crescendo de maneira bastante acentuada nos últimos dois anos, pois impulsionados pelo preço e sua estabilidade, facilidade na venda e na manutenção do pimental, os agricultores a cada ano procuram aumentar a área cultivada.

Com podemos observar abaixo (Figura 7), nos últimos anos, a soma total de pés de pimentas implantados no lote dos oito agricultores entrevistados aumentou significativamente. Em 2010, diante de uma queda no preço da pimenta, os agricultores deixaram de plantar, mas mesmo assim mantiveram a cultura em suas terras.

Figura 7 - Somatório do número de pés de pimenta-do-reino implantados, entre 2008 e 2013, por oito agricultores familiares no assentamento Luiz Inácio - Paragominas PA

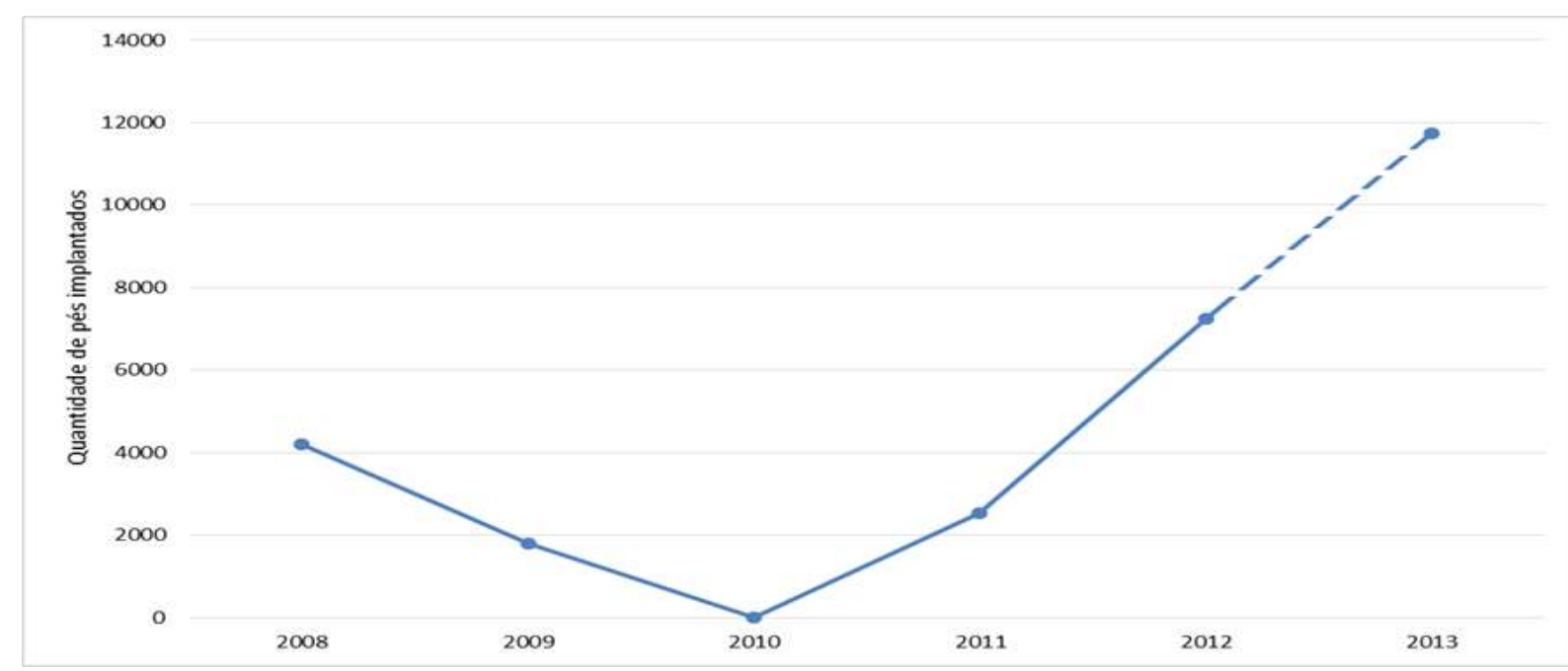

Fonte: Pesquisa de Campo da Especialização em Agriculturas Amazônicas e Desenvolvimento Agroambiental da Universidade Federal do Pará (2012)

A partir de 2011, é notável o aumento do ritmo de implantação de pimenta-do-reino, e a projeção para 2013 é que os valores somados dos oito agricultores deem uma resultante de 11.750 pés no assentamento.

Acompanhando o aumento de número de pés de pimenta implantados, a área cultivada no assentamento também sofreu importante crescimento.

A soma da área plantada pelos oito agricultores entrevistados era de 0,84ha em 2008, entre 2009 e 2010 a área plantada se manteve constante com 1,2ha (Figura 8). Entretanto a 


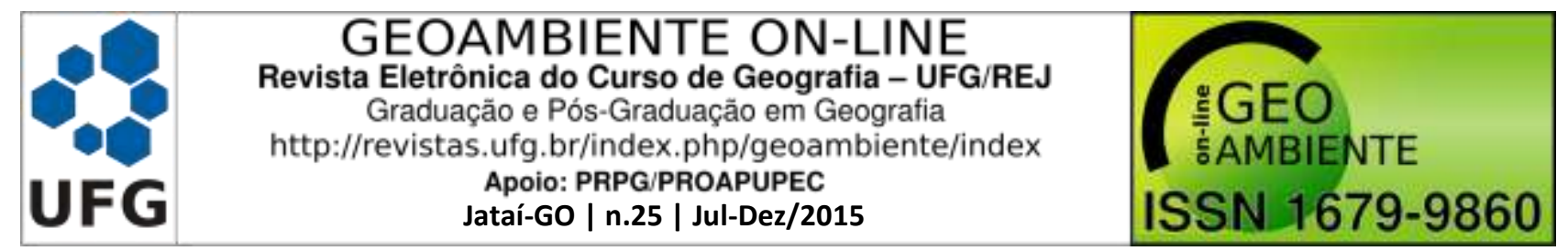

partir de 2012 houve o "boom" da pimenta-do-reino dentro do assentamento, com 3,16 ha plantados.

Figura 8 - Soma da área de pimenta-do-reino plantada entre 2008 e 2013, por oito agricultores familiares no assentamento Luiz Inácio - Paragominas PA

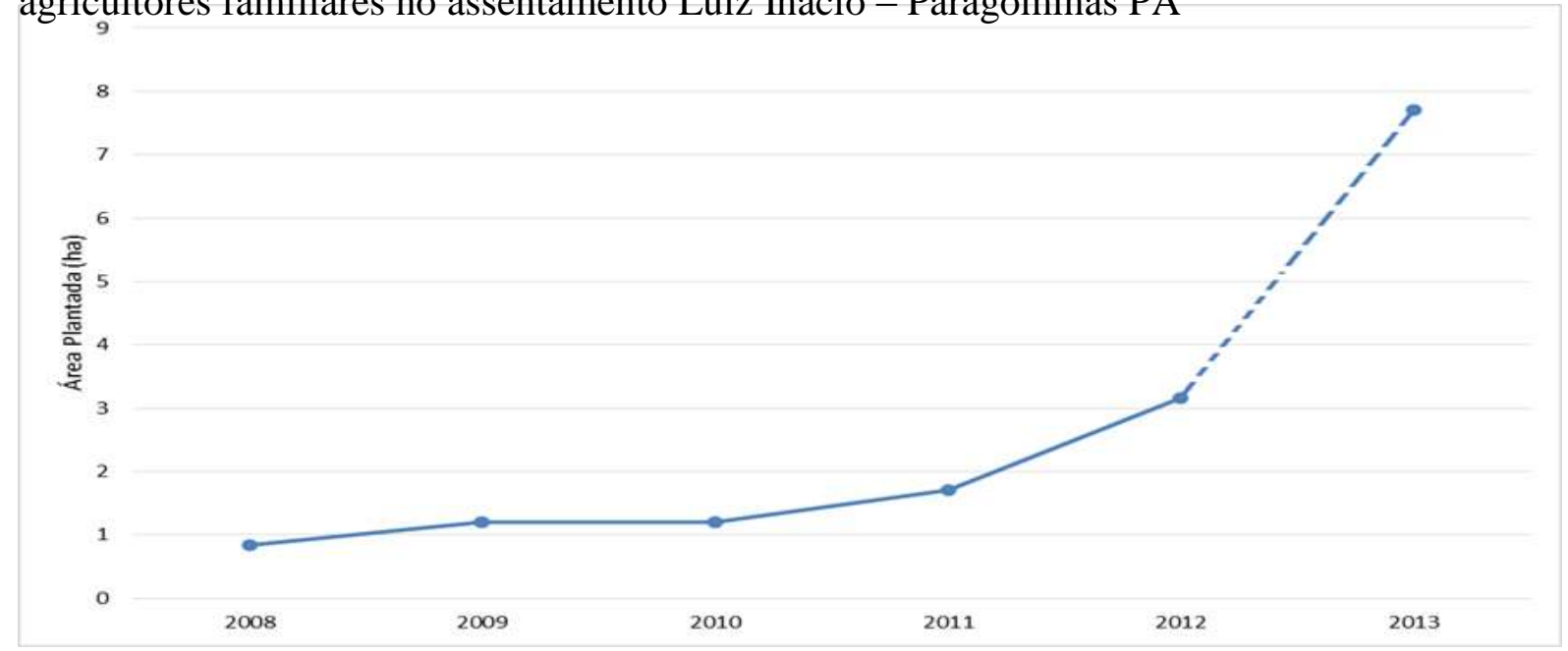

Fonte: Pesquisa de Campo da Especialização em Agriculturas Amazônicas e Desenvolvimento Agroambiental da Universidade Federal do Pará (2012)

Como todos os agricultores estavam preparados para aumentar a área plantada, a projeção para 2013 e de se totalizar uma área de 7,7 ha de pimenta-do-reino entre os agricultores entrevistados.

\section{Recursos para início da atividade}

As principais fontes de renda dos agricultores do assentamento que iniciaram o cultivo da pimenta, são provenientes das atividades agrícolas realizadas no próprio lote (com a plantação de roça de mandioca, milho, arroz e feijão).

Um importante fator de diferenciação das famílias quanto às possibilidades de introdução de uma nova atividade, são referentes às condições financeiras. Essas condições são determinantes do ritmo de implantação do pimental e definem a estrutura atual do plantio, em termos de número de pés e de área plantada. Foi observado que existem dois grandes tipos de agricultores que produzem pimenta. $\mathrm{O}$ tipo 1 refere-se a agricultores que tem pouco capital inicial para investir no cultivo da pimenta (tabela 1), portanto a implantação é realizada de 


\section{GEOAMBIENTE ON-LINE \\ Revista Eletrônica do Curso de Geografia - UFG/REJ \\ Graduação e Pós-Graduaçăo em Geografia \\ http://revistas.ufg.br/index.php/geoambiente/index \\ Apoio: PRPG/PROAPUPEC \\ Jataí-GO | n.25 | Jul-Dez/2015}

uma maneira paulatina. Esses agricultores se concentram na Vila Ribeirinho representando $38 \%$ do total de famílias que inovaram com a pimenta.

O tipo 2 são os agricultores que tem um maior capital inicial para investimento na pimenta (Tabela 1) e se concentram na Vila Cacimbão, representando $62 \%$ de famílias que tem a pimenta como nova atividade produtiva. Assim, desde o início eles implantam uma quantidade maior de pés de pimenta, e o ritmo de implantação é feito em uma quantidade relativamente grande se comparado aos agricultores citados anteriormente, além disso, eles contratam mão-de-obra para ajudar no plantio.

Tabela 1 - Produtores com menor e maior capital inicial para iniciar o cultivo da pimenta-doreino.

\begin{tabular}{lll}
\hline & Tipo 1 & Tipo 2 \\
\hline Ano de chegada ao assentamento. & $2005^{*}(1998-2009)^{* *}$ & $2007 *(2004-2009)^{* *}$ \\
Ano de início da atividade produtiva. & $2012^{*}(2011-2012)^{* *}$ & $2010 *(2008-2012)^{* *}$ \\
Pés plantados no início. & $275^{*}(100-700)^{* *}$ & $2100 *(1500-3500)^{* *}$ \\
Quantidade atual de pés. & $300^{*}(250-700)^{* *}$ & $3950 *(1500-4930)^{* *}$ \\
Área plantada no início (hectares). & $0,055^{*}(0,02-0,14)^{* *}$ & $0,42 *(0,3-0,7)^{* *}$ \\
Área total implantada (hectares). & $0,06^{*}(0,05-0,14)^{* *}$ & $0,42 *(0,3-0,7)^{* *}$ \\
Média da renda (R\$/mês). & $659,5^{*}(600-1000)^{* *}$ & $3.084 *(2666-4751)^{* *}$ \\
\hline
\end{tabular}

Fonte: Pesquisa de Campo da Especialização em Agriculturas Amazônicas e Desenvolvimento Agroambiental da Universidade Federal do Pará (2012)

*Mediana **Mínimo e máximo

Os fatores que distinguem os agricultores com menos e com mais capital inicial são a quantidade de pés plantados no início (esse junto com a área são os principais fatores). Os agricultores mais capitalizados geralmente retiram seus recursos de atividades como o excedente da produção do lote, do comércio e aluguel de equipamentos agrícolas. Já os agricultores menos capitalizados retiram sua renda principalmente na forma de venda de mãode-obra e de auxílios do governo.

Os agricultores querem, com o auxílio financeiro que a pimenta está proporcionando, iniciar a criação de gado. Segundo a FAO (1999), o gado pode ser considerado como uma das melhores poupanças para muitos agricultores. Dois agricultores que já tem retorno financeiro da pimenta, estão iniciando a implantação de pasto para futuramente criar gado em seu lote, entretanto, com o início da atividade pecuária, os agricultores não pensão em parar de cultivar 


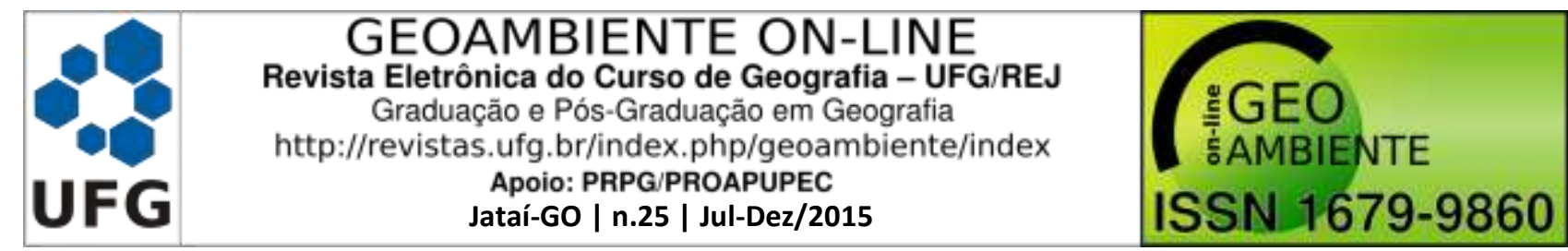

a pimenta, apenas pretendem diminuir o ritmo de pés plantados por ano e manter a estabilidade.

Todos os agricultores que iniciaram o cultivo da pimenta em seu sistema de produção no assentamento Luiz Inácio já têm a experiência, e portanto, conhecimentos, com o cultivo da pimenta-do-reino, pois sua origem está localizada nas cidades que têm ou tiveram importância na produção de pimenta na região do nordeste paraense, como em Capitão Poço, Garrafão do Norte, Ourém e Nova Esperança do Piriá. Essa influência e experiência que as famílias carregam vêm principalmente de trabalhos feitos anteriormente para grandes produtores de pimenta.

Vários são os tipos de experiência vivenciadas pelos agricultores, sendo elas: 1) Experiências adquiridas trabalhando para grandes produtores de pimenta-do-reino do nordeste paraense $(43 \%)$; 2) trabalhando para a própria família que produzia pimenta no nordeste paraense e em cidades do Maranhão (43\%); 3) conhecimento foi adquirido com observações de outros produtores também do nordeste paraense (14\%).

Tais experiências envolvem o tipo de solo correto para o plantio, época de plantio e colheita, estacas certas para fixação da pimenta, controle na poda, quais os melhores cultivares para a região, como fazer a adubação, controle de pragas e doenças, uso de agrotóxicos, proteção das mudas, capina, cobertura morta no pé da pimenta, proteção das mudas recém plantadas. Em suma os agricultores devem iniciar tendo o conhecimento básico dos tratos culturais para a manutenção do pimental.

\section{Projeto dos agricultores}

Quanto mais os agricultores vão se estabilizando no lote, mais eles querem diversificar a produção. Esse processo de diversificação poderá ser acelerado pelo retorno financeiro que a pimenta está trazendo para as famílias que a produzem e que irão produzir. Entretanto essa diversificação difere entre os produtores com maior capital e os com menor capital.

Os produtores que tem menor capital para iniciar a cultura da pimenta em seu lote procuram diversificar em vários cultivos como a roça de mandioca, o milho, o feijão e o arroz. Já os produtores com maior capital estão tendendo a se especializar em determinada demanda no caso a pimenta e gado. Mesmo com a tendência de alguns agricultores iniciarem a 


\section{GEOAMBIENTE ON-LINE \\ Revista Eletrônica do Curso de Geografia - UFG/REJ \\ Graduação e Pós-Graduaçăo em Geografia \\ http://revistas.ufg.br/index.php/geoambiente/index \\ Apoio: PRPG/PROAPUPEC \\ Jataí-GO | n.25 | Jul-Dez/2015}

atividade pecuária em seus lotes, fica claro na pesquisa que eles não pretendem deixar de plantar a pimenta-do-reino.

É importante citar que os produtores com o maior capital deixaram de fazer o roçado de mandioca por alegarem que além do trabalho ser penoso, não possibilita o retorno financeiro que a pimenta proporciona. Muitos produtores não possuem veículos para transportar a produção, o que, aliado à distância e à carência de transporte público, leva também a uma diminuição da produção pelas dificuldades de escoamento da mesma (KOMARCHESKI, 2012), fazendo com que a busca pelo cultivo da pimenta seja mais requerida pelos agricultores.

Fazendo-se um breve comparativo entre a produção de pimenta-do-reino e de mandioca, em 2012, no lote de dois produtores do assentamento visitado na pesquisa de campo, podemos observar as vantagens da pimenta-do-reino frente à mandioca (Tabela 2).

Tabela 2 - Comparação entre a cultura da pimenta-do-reino e da mandioca no Nordeste paraense.

\begin{tabular}{|c|c|c|c|c|c|}
\hline & $\begin{array}{l}\text { Preço por } \\
\mathrm{kg}\end{array}$ & $\begin{array}{l}\text { Área } \\
\text { plantada }\end{array}$ & $\begin{array}{l}\text { Produção esperada por } \\
\text { área no lote }\end{array}$ & Produtividade & $\begin{array}{l}\text { Tempo de espera para } \\
\text { a colheita }\end{array}$ \\
\hline $\begin{array}{l}\text { Pimenta-do- } \\
\text { reino }\end{array}$ & $\mathrm{R} \$ 11,00$ & $0,48 \mathrm{ha}$ & $1.280 \mathrm{~kg}$ & $2.666 \mathrm{~kg} / \mathrm{ha}$ & 3 anos \\
\hline Mandioca & $\mathrm{R} \$ 2,60$ & $1,8 \mathrm{ha}$ & $3.000 \mathrm{~kg}$ & $1.667 \mathrm{~kg} / \mathrm{ha}$ & 1 ano \\
\hline
\end{tabular}

Fonte: Pesquisa de Campo da Especialização em Agriculturas Amazônicas e Desenvolvimento Agroambiental da Universidade Federal do Pará (2012)

Os agricultores se referem mais as vantagens da pimenta-do-reino sobre vários cultivos, entretanto, é importante destacar que há uma unanimidade dos agricultores no que se refere ao tempo de espera para o retorno financeiro da pimenta.

Segundo Filgueiras et al. (2012), em 2008 o estado do Pará foi responsável por 69,6 mil toneladas de pimenta produzida, representando $80,45 \%$ da produção nacional, com produtividade de $2.335 \mathrm{~kg} / \mathrm{ha}$. Em 2010 destacou-se no Pará a região nordeste com 27.952 toneladas, representando 71,24\% do total deste ano (IDESP, 2010 apud. Filgueiras et al., 2012). 


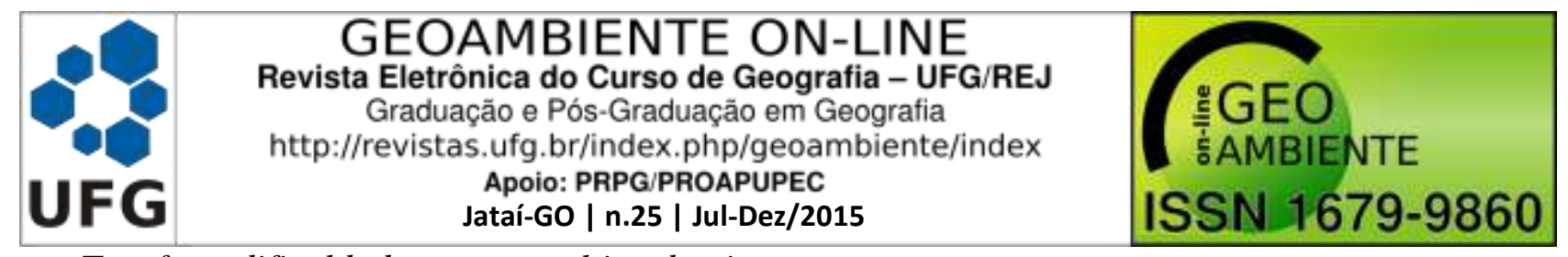

Trunfos e dificuldades para o cultivo da pimenta no assentamento

Fica claro durante a pesquisa que existem trunfos e dificuldades no cultivo da pimenta-do-reino para a região. Dentre as principais vantagens está o escoamento da produção, pois nesse aspecto a vantagem se destaca em o produtor não ter que se deslocar para vender a pimenta, pois o atravessador (geralmente de Nova Esperança do Piriá) vai onde está o produtor, facilitando assim a venda.

O preço é outra vantagem, sua estabilidade nos últimos dois anos fez com que vários agricultores iniciassem a atividade em seu lote, entretanto, mesmo se o preço baixar muito (até R\$ 5,00), para eles ainda é vantajoso, pois os benefícios (manutenção, facilidade no manejo) se comparados com a roça de mandioca são bem acentuados.

As condições do meio biofísico encontradas em algumas áreas do assentamento são um trunfo. As condições edafoclimáticas são bastante propícias para a cultura na região, além disso, ainda há bastante mata no assentamento e os agricultores escolhem essas áreas para implantação do pimental, assim os solos são bem menos desgastados que se tivessem sido utilizados por alguns anos com finalidade agrícola.

As áreas de mata ainda oferecem, geralmente, madeira-de-lei, que serve de apoio para fixar as raízes, já que a pimenteira-do-reino precisa de tutor. Dentre as quatro vilas estudadas no assentamento a mais procurado é a do Cacimbão, pelas suas características edáficas, pois na região o solo predominante é do tipo latossolo. Segundo Pinto (2009), tipo de solo predominante no município é o latossolo amarelo distrófico, que cobre $95 \%$ do território municipal.

A cultura da pimenteira-do-reino é feita em terrenos de terra firme, não sendo utilizados os solos de várzeas, devido a sua condição de encharcamento e excesso de umidade. Fatores estes que os tornam impróprios para o cultivo, pela deficiência de oxigênio que prejudica o desenvolvimento do sistema radicular da planta, e consequentemente, o aparecimento de fungos patogênicos (BAENA \& RODRIGUES, 2005).

Entre as classes de solos de terra firme que reúnem condições edáficas e qualidades para o cultivo da pimenteira-do-reino estão os latossolos e os argissolos, que são os dominantes, com aproximadamente $48 \%$ e $30 \%$, respectivamente, da superfície total da Amazônia brasileira. (BAENA \& RODRIGUES, 2005). 


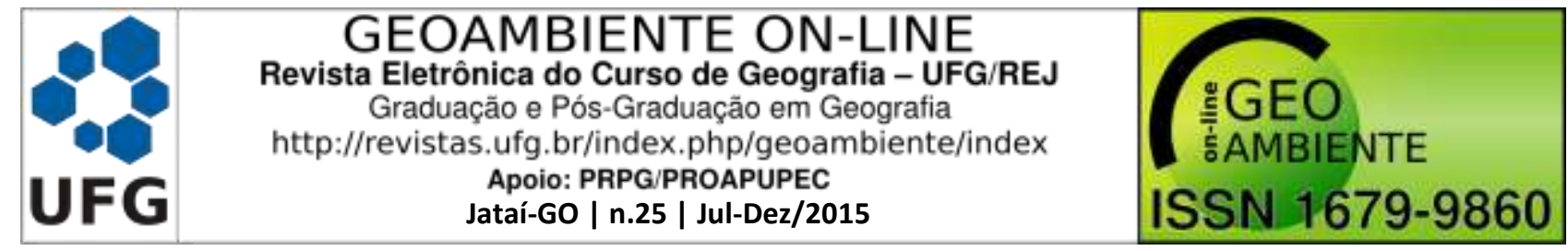

Outra característica vantajosa da vila Cacimbão é sua característica topográfica, propícia para o cultivo da pimenta, pois, segundo Baena e Rodrigues (2005), o relevo preferencialmente plano e suave ondulado (declividade de $8 \%$ a $20 \%$ ) recebe perfeitamente o cultivo da pimenta. Dados do IMAZON (2009), mostram que trinta e cinco por cento do território de Paragominas possui altitudes que variam entre 100 e 150 metros.

O clima do município de Paragominas, segundo a classificação climática de Köppen, é do tipo Ami (clima tropical chuvoso, com expressivo período de estiagem), com temperatura média anual de $26,3^{\circ} \mathrm{C}$ e umidade relativa do ar média de $81 \%$. A pluviosidade média anual é de 1.700 milímetros, com um período mais chuvoso, entre os meses de dezembro a maio, e outro mais seco entre junho e novembro (BASTOS, 2005), essas características climáticas fazem com que a região seja ideal para o cultivo da pimenta. Segundo dados da EMBRAPA/SEDE (2004), o clima ideal para a cultura da pimenta-do-reino é o quente e úmido, com precipitação pluviométrica acima de $1.800 \mathrm{~mm} / \mathrm{ano}$ e boa distribuição de chuvas durante o ano. A umidade relativa do ar deve ser superior a $80 \%$ e a temperatura média, entre $25^{\circ} \mathrm{C}$ e $27^{\circ} \mathrm{C}$

Durante as entrevistas nenhum agricultor se queixou de algum tipo de doença que atacasse o pimental. Muito provavelmente isso devesse ao fato dos plantios serem novos e de estarem relativamente afastados de outros cultivos de pimenta, o que isola e protege as áreas de pimenta do assentamento. Segundo a EMBRAPA SEDE (2004), é necessário evitar áreas onde foram cultivadas anteriormente cucurbitáceas (pepino, maxixe, melão, melancia, abóbora) bem como áreas onde têm ou foram utilizadas com pimentais contaminados por doenças como podridão das raízes, mosaico do pepino e fusariose.

É inevitável que chegue ao ponto de fitopatógenos atacarem os pimentais da região pois, com o aumento excessivo do cultivo da pimenta ocorrera esse tipo de competição entretanto, ainda não há relato de ataques de doenças segundo os agricultores.

O manejo do pimental foi outro trunfo apontada pelos agricultores, pois o cultivo da pimenta depois de implantada, não precisa de tantos cuidados e dá mais liberdade para o agricultor.

Existem também várias dificuldades apontadas pelos agricultores para o cultivo da pimenta no assentamento. Dentre elas se destacam a implantação da cultura, pois desmatar uma área ou deixa-la própria para plantar a pimenta é um serviço bastante penoso, principalmente no que se refere à fixação das estacas de madeira no solo. A dificuldade para 


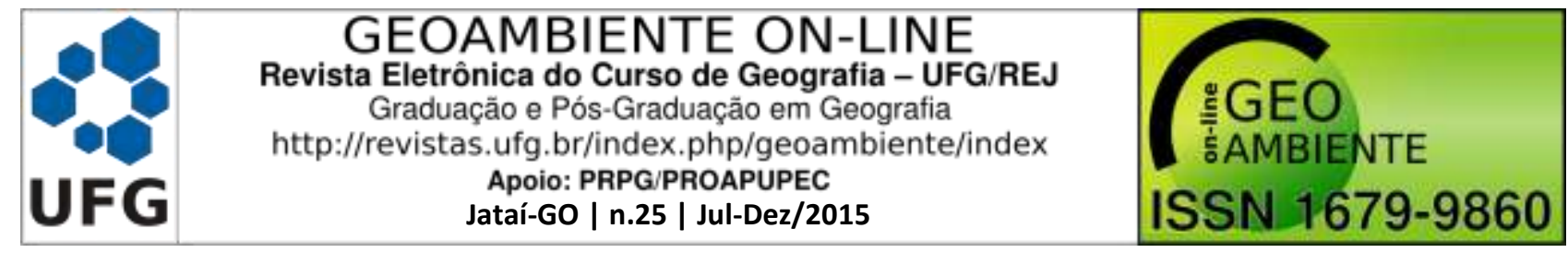

conseguir as estacas, quando não estão disponíveis no lote que foi desmatado, também é outro obstáculo apontada, atualmente o preço de uma estaca própria para servir de tutor (preferencialmente madeira-de-lei para aguentar todo o ciclo de vida da pimenta que na região segundo os agricultores dura em média sete anos) está em torno de $\mathrm{R} \$ 15,00$.

O fogo acidental, apesar de não ser frequente nos pimentais da região, preocupa bastante, já que todo ano na estação seca, principalmente entre os meses de setembro e novembro, o Assentamento sofre graves consequências, queimando grandes áreas da região, o que põe em risco os plantios.

A falta de políticas públicas para alavancar e apoiar o desenvolvimento do cultivo da pimenta no assentamento, assim como de qualquer atividade produtiva, consiste em um descontentamento generalizado. Em período de preparo de área, um trator é disponibilizado pela prefeitura para atender os assentados em Luiz Inácio, mas ele não chega a atender nem $5 \%$ deles. Nenhum agricultor entrevistado que planta pimenta foi beneficiado por esse tipo de maquinário, o que ocasiona um descontentamento importante, pois a mão-de-obra para iniciar o cultivo é muito pesada. Eles também mencionaram como carência de apoio a falta de assistência técnica e a precária manutenção das estradas. Nesse sentido, um dos agricultores nos relatou que: "precisa de ajuda de gente de fora para arrumar a estrada e o maquinário. Várias pessoas querem plantar mas não sabem".

\section{Considerações finais}

De acordo com a pesquisa, o processo de introdução de novas atividades produtivas acontece principalmente devido à perspectiva das famílias de ter maior estabilidade financeira. É importante destacar que há outras iniciativas de mudança nos sistemas de produção, como a implantação de pasto para iniciar a criação de gado.

A introdução de novas atividades dentro do assentamento inicia com a observação das famílias das demandas do mercado, e a busca de um produto que proporcione uma renda que atenda às suas necessidades financeiras. Aliado a isso, as condições ambientais da região contribuem para que a adoção da pimenta-do-reino seja bastante favorável para os agricultores familiares que adotaram essa cultura no seu sistema de produção. Percebe-se que não pode haver o desenvolvimento de uma nova atividade produtiva sem que haja um 


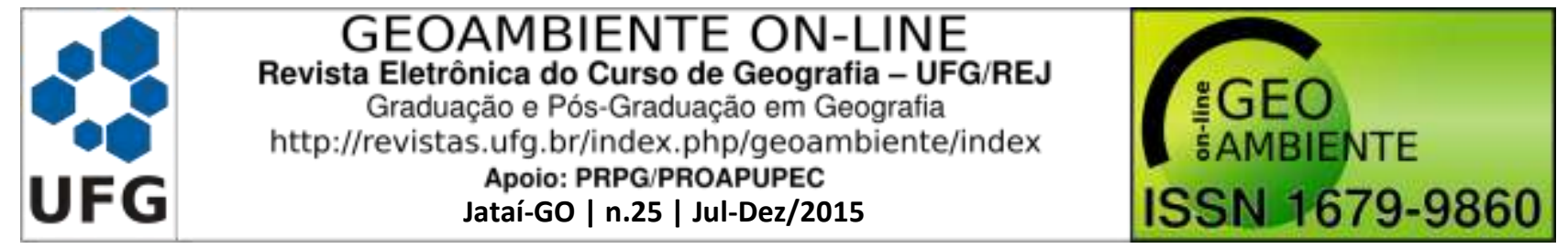

conhecimento prévio de como maneja-las, mesmo considerando-se os interesses comerciais e financeiros.

Esta pesquisa contribui para entender as possibilidades de mudanças nas atividades produtivas, considerando os fatores limitantes e os fatores que contribuem para essas mudanças que. As informações dessa pesquisa podem subsidiar um apoio ao planejamento dos agricultores sobre a implementação da pimenta do reino.

Referências bibliográficas

BAENA, A. R. C.; RODRIGUES, T. E. Sistema de Produção da Pimenteira-do-reino. Embrapa Amazônia Oriental. Belém, dez. 2005. Solos. Disponível em: $<$ http://sistemasdeproducao.cnptia.embrapa.br/FontesHTML/Pimenta/PimenteiradoReino/pag inas/solos.htm\#condicoes>. Acesso em: 09 fev. 2013.

BARBOSA, F. B. C.; FALESI, Í. C. Modernização da agricultura e desenvolvimento do Pará. Instituto de Pesquisa Aplicada em Desenvolvimento Econômico Sustentável - IPADES. Belém/PA, 2011.

BASTOS, T. X.; SILVA, G. F. G.; PACHECO, N. A.; FIGUEIREDO, R. O. Informações agroclimáticas do município de Paragominas para o planejamento agrícola. In: XIV CONGRESSO BRASILEIRO DE METEOROLOGIA, 2006, Florianópolis. Anais Eletrônicos... Florianópolis: SBMET, 2006. Disponível em: <http://www.cbmet.com/cbmfiles/14-ba598d933112b1c2d224097080cee212.pdf> Acesso em: 11 fev. 2013.

EMBRAPA. Manual Segurança e Qualidade para a Cultura da Pimenta-do-Reino. Brasília: EMBRAPA/SEDE, 2004. 65 p. (Qualidade e Segurança dos Alimentos). Projeto PAS Campo. Convênio CNI/SENAI/SEBRAE/EMBRAPA. Disponível em:<http://www.infoteca.cnptia.embrapa.br/bitstream/doc/111893/1/MANUALSEGURANC AQUALIDADEparaaculturadapimentadoreino.pdf> Acesso em: 29 mar. 2013.

FAO - Food and Agriculture Organization of United Nations. The state of food insecurity in the $\quad 1999 . \quad$ Dorld. em: <http://www.fao.org/ag/againfo/programmes/pt/lead/toolbox/Mixed1/CropLive.htm> Acesso em: 12 mar. 2013. 


\begin{tabular}{|c|c|c|}
\hline & $\begin{array}{c}\text { GEOAMBIENTE ON-LINE } \\
\text { Revista Eletrônica do Curso de Geografia - UFG/REJ } \\
\text { Graduação e Pós-Graduaçäo em Geografia } \\
\text { http://revistas.ufg.br/index.php/geoambiente/index } \\
\text { Apoio: PRPG/PROAPUPEC } \\
\text { Jataí-GO | n.25 | Jul-Dez/2015 }\end{array}$ & $\begin{array}{l}\text { ¿GEO } \\
\text { 亡.AMBIENTE } \\
\text { ISSN } 1679-9860\end{array}$ \\
\hline
\end{tabular}

FILGUEIRAS, G. C.; HOMMA, A. K. O.; SANTOS, M. A. S. Conjuntura do mercado da pimenta-do-reino no Brasil e no mundo. In: WORKSHOP DA PIMENTA DO REINO DO ESTADO DO PARÁ, 1., 2009, Belém, PA. Situação atual e alternativa para a produção sustentável. Belém, PA: Embrapa Amazônia Oriental, 2009. Disponível em: <http://www.alice.cnptia.embrapa.br/handle/doc/660437>. Acesso em: 07 mar. 2013.

FILGUEIRAS, G. C. ; HOMMA, A. K. O. ; SANTOS, M. A. S. dos ; MOTA JUNIOR, K. J. A. ; SILVA, S. C. . A exploração da pimenta-do-reino como alternativa de sustentabilidade socioeconômica e ambiental do Pará. In: VI Encontro Associação Nacional de PósGraduação e Pesquisa em Ambiente e Sociedade, 2012, Belém/PA. Anais do VI ENANPPAS, 2012.

HOMMA, A. K. O.; FERREIRA, C. A. P.; DUARTE, M.L.R. Mercado e comercialização. 1ed. Belém: Embrapa Amazônia Oriental, 2005. Disponível em: < http://sistemasdeproducao.cnptia.embrapa.br/FontesHTML/Pimenta/PimenteiradoReino/pagin as/mercado.htm>. Acesso em: 31 mar. 2013.

KOMARCHESKI, R. Sustentabilidade socioambiental da produção de farinha de Mandioca em Guaraqueçaba - PR. Curitiba, 2012. Dissertação (Mestrado) - Universidade Federal do Paraná - Programa de Pós-graduação em Meio ambiente e desenvolvimento. Disponível em: < http://hdl.handle.net/1884/29349> Acesso em: 13 mar. 2013.

LEFORT, J. Inovação tecnológica e experimentação no meio rural. Brasília: DAS / CIRAD / CPAC / EMBRAPA, 1990, 11 p.

NASCIMENTO, T.S. et al. Aspectos Sócio-Ambientais da Agricultura Familiar na Região da Transamazônica, Estado do Pará. In: CONGRESSO BRASILEIRO DE SISTEMAS DE PRODUÇÃO, 7., 2007, Fortaleza. Anais... Fortaleza, 2007. Disponível em: <http://www.cnpat.embrapa.br/sbsp/anais/Trab_Format_PDF/166.pdf> Acesso em: 29 mar. 2013.

OCDE - Organização para Cooperação Econômica e Desenvolvimento. Manual de Oslo: proposta de diretrizes para coleta e interpretação de dados sobre inovação tecnológica. Rio $\begin{array}{lllll}\text { de Janeiro: } & \text { FINEP. } & \text { Disponível }\end{array}$ <http://www.finep.gov.br/imprensa/sala_imprensa/manual_de_oslo.pdf > Acesso em:

13 mar. 2013. 


\begin{tabular}{|c|c|c|}
\hline & $\begin{array}{c}\text { GEOAMBIENTE ON-LINE } \\
\text { Revista Eletrônica do Curso de Geografia - UFG/REJ } \\
\text { Graduação e Pós-Graduaçäo em Geografia } \\
\text { http://revistas.ufg.br/index.php/geoambiente/index } \\
\text { Apoio: PRPG/PROAPUPEC } \\
\text { Jataí-GO | n.25 | Jul-Dez/2015 }\end{array}$ & $\begin{array}{l}\text { ¿GEO } \\
\text { 亡.AMBIENTE } \\
\text { ISSN } 1679-9860\end{array}$ \\
\hline
\end{tabular}

PINTO, A.; AMARAL, P.; SOUZA JR., C.; VERÍSSIMO, A.; SALOMÃO, R.; GOMES, G.;

BALIEIRO, C. Diagnóstico socioeconômico e florestal do município de Paragominas. Belém, PA: Instituto do Homem e Meio Ambiente da Amazônia - Imazon, 2009. 65 p. Relatório Técnico. Disponível em $<$ http://www.imazon.org.br/publicacoes/outros/diagnosticosocioeconomico-e-florestal-do >. Acesso em: 09 mai. 2013.

POLTRONIERI, M. C.; ALBUQUERQUE, F. C.; DUARTE, M. L. R. Sistema de Produção da Pimenteira-do-reino. Embrapa Amazônia Oriental. Belém, dez. 2005. Cultivares. Disponível em:

http://sistemasdeproducao.cnptia.embrapa.br/FontesHTML/Pimenta/PimenteiradoReino/pagin as/cultivares.htm>. Acesso em: 07 mar. 2013.

REINJNTJES, C; HAVERKORT, B; WATERS-BAYER, A. Agricultura para o Futuro: Uma Introdução à Agricultura Sustentável e de Baixo Uso de Insumos Externos. Tradução de John Cunha Comeford. Rio de Janeiro: AS-PTA, 1994.

REVISTA CAMPO E NEGÓCIOS. Pimenta-do-reino tem valor agregado. Revista Campo e Negócios, Uberlândia, 01 out, 2012. Ano X, $\mathrm{N}^{\circ}$ 117. Disponível em: <http://www.revistacampoenegocios.com.br/anteriores/201211/index.php?referencia=capacnhf $>$ Acesso em; 11 fev. 2013.

SILVA, J. P. L.; SOUSA, A. S.; SILVA, T. S. S.; SANTOS, M. A. S. Comportamento de preço da pimenta-do-reino branca no estado do Pará no período 2002 - 2011. 2012. In: REUNIÃO ANUAL DA SBPC, 64. 2012, São Luís. Anais eletrônicos... São Luís: SBPC, 2012. Disponível em: <http://www.sbpcnet.org.br/livro/64ra/resumos/resumos/8358.htm>. Acesso em: 17 jan. 2013. 